\title{
Avant-propos
}

Foreword

\section{Luc de Heusch}

\section{OpenEdition}

\section{Journals}

Édition électronique

URL : http://journals.openedition.org/span/86

DOI : 10.4000/span.86

ISSN : 2268-1558

\section{Éditeur}

École pratique des hautes études. Sciences humaines

\section{Édition imprimée}

Date de publication : 1 septembre 1975

Pagination : $3-4$

ISSN : 0294-7080

\section{Référence électronique}

Luc de Heusch, « Avant-propos », Systèmes de pensée en Afrique noire [En ligne], 1 | 1975, mis en ligne le 08 juillet 2013, consulté le 22 septembre 2020. URL : http://journals.openedition.org/span/86 ; DOI : https://doi.org/10.4000/span.86 


\section{AVANT PROPOS}

par Luc de HEUSCH

Germaine DIETERLEN, qui poursuit inlassablement au Mali 1'enquête décisive inaugurée par Marcel GRIAULE, anima de 1969 à 1973 au C.N.R.S. un groupe de recherches voué à l'étude des religions africaines. Le rayonnement de son enseignement et de ses travaux contribua largement au développement de l'anthropologie religieuse et en 1974, la vè Section de l'E.P.H.E. décida la création du Laboratoire Associé "Systèmes de Pensée en Afrique Noire" dont la direction fut confiée à Michel CARTRY et à moi-même. Le principal objectif du Laboratoire est de multiplier, d'approfondix les expériences du terrain et d'assurer des échanges de vues réguliers entre les chercheurs -européens et africainspour une mise en commun des observations et des analyses.

Le présent cahier est le premier témoignage de ces "travaux pratiques". En prenant le risque de cette publication, nous avons été guidés par le souci de mettre en circulation notes et esquisses à partir de quoi s'élaboreront monographies et articles destinés aux revues spêcialisées. Les itinéraires sont divers, les parcours récents ou anciens. Ce premier cahier ne pouvait être que bigarré. Il livre pêle-mêle des observations sur la religion et la sociétë, la pensêe historique et mythique, les conduites rituelles, les cultes de possession, l'écriture divinatoiro, la sorcellerie. Les méthodes d'enquête varient elles aussi d'une région à l'autre. On remarquera cependant que le travail d'équipe tend à se développer (recherches sur les Dogon, les Bambara, les Soninké, les Minyanka ); des contacts s'établissent de plus en plus fréquemment entre les chercheurs travaillant sur des terrains voisins. D'évidence l'anthropologue ne se satisfait plus de la solitude à laquelle le vouaient la méthodologie et l'idéologie de l'école fonctionnaliste. Il tend aussi à briser le cadre abstrait où se situait la relation enquêteurenquêté : l'utilisation des moyens audio-visuels rend possible, selon 1 'expression de Jean ROUCH, une anthropologie partagée. La projection du film d'un rituel à ceux-là même qui en ont été les acteurs, l'audition répétée de textes enregistrés in situ par les intéressés, créent un nouveau type de relation, source d'approfondissements multiples.

Plusieurs d'entre nous partagent la conviction que la transmission des connaissances et des pouvoirs qui $y$ sont attachés se fait, en Afrique, par paliers successifs; il arrive que le processus initiatique impose à l'enquêteur la traversée de divers "niveaux d'interprétation" ; ne pas les distinguer expose le commentateur à bien des contresens lorsqu'il aborde, au terme de sa recherche (mais celle-ci est-elle jamais close ?) l'unité profonde, consciente ou inconsciente, de l'édifice symbolique. Ceci implique la confrontation permanente des schémas explicatifs aux modèles proposés par les intéressés eux-mêmes. 
Le développement très inégal des études d'anthropologie religieuse dans l'ensemble de l'Afrique ne permet pas encore de discerner clairement les contours symboliques communs à plusieurs ensembles ethniques. L'on entrevoit cependant I'ores et déjà que bien des cloisonnements culturels prématurément établis devront être abolis. Des recoupements inattendus se dessinent ici et là : entre les religions Bambara et Minyanka, entre certains aspects de la royauté sacrée en Afrique occidentale et en Afrique centrale, par exemple.

Aussi bien le second objectif du Laboratoire est-il de créer de meilleures conditions d'une étroite association entre la recherche sur le terrain et l'analyse historique et thếorique. Dans ce domaine, les études comparatives en cours sur les systèmes divinatoires et les systèmes graphiques, comme les résultats des deux colloques organisés par le C.N.R.S. respectivement en 1968 et 1971 sur le phénomène de la possession et la notion de personne, sont des plus encourageants (1).

La mythologie comparée se développe à son tour. Des ensembles symboliques se relient progressivement les uns aux autres sur de vastes espaces (1'aire d'expansion du Mandé, celle des royaumes bantous, etc.). Les religions africaines ont cessé de nous apparaftre comme autant de monades closes, en dépit de leur évident enracinement dans des structures socio-économiques toujours particulières, dont la méconnaissance les renarait inintelligibles.

Il ne s'agit évidemment pas de postuler l'unité et l'uniformité de la pensée africaine traditionnelle, mais, au contraire, d'enregistrer ses multiples variations et transformations, sa dialectique propre, partout où le grand jeu symbolique s'interpose entre l'homme et la nature, le travail et ses résultats, le sexe et la société, la vie et la mort.

(1) Ces deux rencontres furent organisées, d'une part par $R$. BASTIDE et J. ROUCH, par G. DIETERLEN d'autre part. 